\title{
Die Qualifikation als Gruppen- oder Verbandskläger im kollektiven Rechtsschutz
}

Einer für alle, aber wer nur?

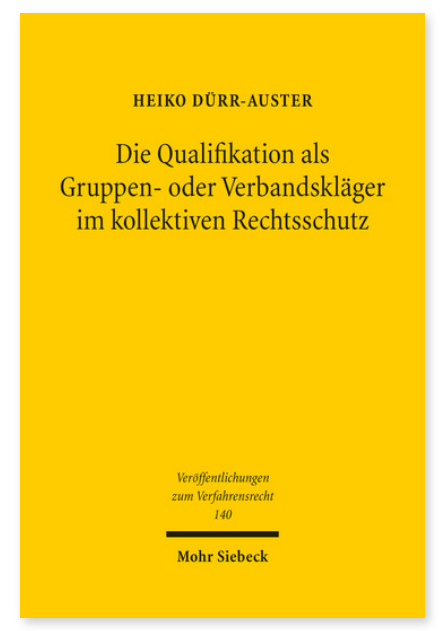

2017. XXV, 445 Seiten. VVerfR 140

ISBN 978-3-16-155401-8

DOI 10.1628/978-3-16-155401-8

eBook PDF 99,00€

ISBN 978-3-16-155400-1

fadengeheftete Broschur 99,00€
Im Juni 2013 erließ die Europäische Kommission eine Empfehlung zum kollektiven Privatrechtsschutz. Darin ist unter anderem eine sog. Vertretungsklage vorgesehen, die von privatrechtlichen »Einrichtungen« im Namen aller Betroffenen erhoben werden kann. Aus diesem Anlass analysiert Heiko Dürr-Auster die Verbandsklagerechte im UKlaG, UWG und GWB und stellt sie rechtsvergleichend den Kollektivverfahren des niederländischen Burgerlijk Wetboek gegenüber. Auch unter Berücksichtigung praktischer Erfahrungen erörtert er, welche Organisationen für welche Verfahrensform in Betracht kommen und welche Anforderungen an sie gestellt werden sollten. Im Ergebnis befürwortet der Autor die Repräsentation durch private Interessenorganisationen in Schadenersatzverfahren und hält dabei auch eine kommerzielle Tätigkeit unter bestimmten Voraussetzungen für erforderlich. Für Unterlassungsklageverfahren haben sich die bestehenden Verbandsklagerechte und ihre Hauptakteure seiner Ansicht nach bewährt. An einzelnen Stellen tritt er dennoch für Korrekturen ein.

Heiko Dürr-Auster Geboren 1987; Studium der Rechtswissenschaften an der Universität Konstanz; wissenschaftlicher Mitarbeiter an der Universität Konstanz; 2017 Promotion; seit 2016 Rechtsreferendariat im Bezirk des Oberlandesgerichtes Köln.

\section{Jetzt bestellen:}

https://mohrsiebeck.com/buch/die-qualifikation-als-gruppen-oder-verbandsklaeger-im-kollektiven-rechtsschutz9783161554018?no_cache=1

order@mohrsiebeck.com

Telefon: +49 (0)7071-923-17

Telefax: $+49(0) 7071-51104$ 